\title{
Time Independent Signature Verification using Normalized Weighted Coefficients
}

\author{
Manas Singhal, Manish Trikha, Maitreyee Dutta \\ ME Scholar, Department of E\&C Engineering, NITTTR Chandigarh, India
}

\begin{tabular}{l}
\hline \hline Article Info \\
\hline Article history: \\
Received Mar 18, 2016 \\
Revised May 19, 2016 \\
Accepted Jun 1, 2016 \\
\hline
\end{tabular}

Keyword:

FAR

FRR

Signature verification

Skewness

\begin{abstract}
Signature verification is one of the most widely accepted verification methods in use. The application of handwritten signatures includes the banker's checks, the credit and debit cards issued by banks and various legal documents. The time factor plays an important role in the framing of signature of an individual person. Signatures can be classified as: offline signature verification and online signature verification. In this paper a time independent signature verification using normalized weighted coefficients is presented. If the signature defining parameters are updated regularly according to the weighted coefficients, then the performance of the system can be increased to a significant level. Results show that by taking normalized weighted coefficients the performance parameters, FAR and FRR can be improved significantly.
\end{abstract}

Copyright $\odot 2016$ Institute of Advanced Engineering and Science. All rights reserved.

Corresponding Author:

Manas Singhal,

Department of Electronics and Communication Engineering,

NITTTR Chandigarh, India.

Email: manas.singhal.ec@gmail.com

\section{INTRODUCTION}

Signature verification is widely accepted biometric authentication method. In comparison with the face, thumb impression and various other biometric methods for authentication, handwritten signature verification is a more non-trespassing and convenient way of authenticating information [1]. The signature is a very popular way of the identification of the identity. The application of handwritten signatures includes the banker's checks, the credit and debit cards issued by banks and various legal documents. These are one of the essential part of the current economy [2-3]. These are the primary verification steps using which an individual and an organization makes all of its transactions in real worlds. Most of the money transfers and bill payments are authenticated using signature verification [4]. There are many other authentication techniques like a password or PIN (Personal Identification Number) but the problem with that identifiable data is that it can be forgotten, misplaced, stolen or shared. On the other hand, information values taken from the handwritten signature will be unique to a person and it will be very difficult to forge that one [5]. A signature can be considered as a composition of special characters and flourishes. The signature differentiates a person from another person. In the authentication process using signature a referenced signature should be stored in a computer. It can be stored in the form of an image (.jpg) file. The signature under question can be compared to the stored reference signature for authentic information [6]. There are two different types of approach for the signature verification [7]. These can be classified as: offline signature verification and online signature verification. In offline signature verification input to the system is normally a two dimensional image of the signature and the static information is extracted for comparison [8]. In online signature verification the dynamic user features (like speed, pressure, trajectory, etc.) are extracted during the signing operation using digitizing devices, such as a tablet or touch pad [9]. 
The manual verification of handwritten signatures by humans can be a very difficult task. Thus, an automatic Signature verification system is required. This system will improve the authentication process and will provide a secure means for authorization of legal documents [8].

The objective of this research is

a. To Collect the Handwritten Signature database with a wide span of time.

b. To Extract the features of Handwritten Signature.

c. To Train the Neural Network using extracted dataset.

d. To Match the online signature with stored dataset.

e. To Provide the authentic information.

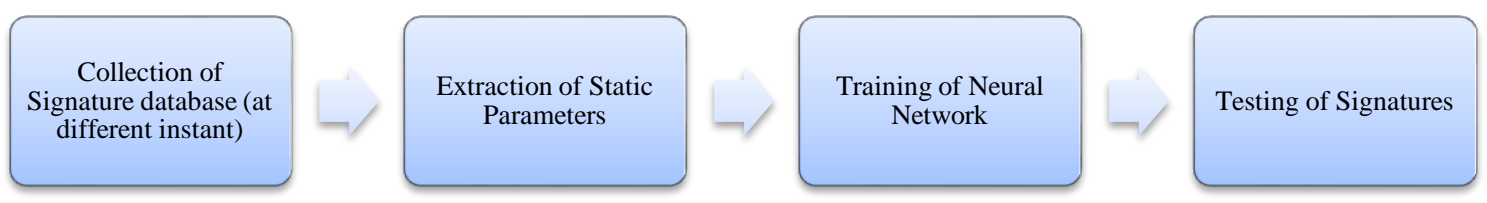

Figure 1. Design Methodology

Figure 1 shows the design methodology used in this paper. First of all the signatures are collected, stored as a reference signature. The static parameters are extracted from these reference signatures. These parameters are updated regularly by new reference signatures. Neural network is trained using these parameters. Signatures are tested using designed system.

\section{ANALYZING PARAMETERS}

\subsection{Identification Parameters}

There are two different types of parameters of signature: Static parameters and dynamic parameters. In case of online signature verification dynamic features of signature are extracted and in case of offline signature verification static parameters of signatures are extracted. In this paper following static parameters of signatures are considered

a. Skewness: Skewness a measure of symmetry. Skewness is defined with reference to the univariate data $\mathrm{X}_{1}, \mathrm{X}_{2}, \ldots \ldots \ldots, \mathrm{X}_{\mathrm{N}}$

$$
\text { Skewness }=\frac{\sum_{i=1}^{N}\left(X-X^{-1}\right) s^{3}}{(N-1) s^{3}}
$$

b. Kurtosis: Kurtosis determines whether the data are peaked or flattened, relative to normal distribution. It highlights the peaks in each segment of signature.

$$
\text { Kutosis }=\frac{\sum_{i=1}^{N}\left(X-X^{-1}\right) s^{4}}{(N-1) s^{4}}
$$

c. Ordinary Moment: It is defined as the ordinary moment of pixels.

d. Entropy: It defines the information content of white pixels in inverted image and is given by

$$
\text { Entropy }=\mathrm{N} * \log _{2} \mathrm{~N}
$$

e. Mean: It defines the mean value of white pixels in inverted image.

f. Orientation: It defines the direction of the signature lines. 


\subsection{Performance Parameters}

The performance of the verification system can be explained using following two parameters

a. False Acceptance Rate (FAR): It is the ratio of false signature acceptance to the total number of tested signatures.

b. False Rejection Rate (FRR): It is the ratio of false rejected signature to the total number of tested signatures.

\section{TIME FACTOR}

One of the most widely accepted verification methods is the signature verification. The Signature of a person may vary by a great amount depending on the situation, when the signature is taken [10-12]. The mood of a particular person may also affect the signature of an individual. There are many such factors that influence the signature of a person, but none of them affects as much as the time duration itself. If a signature is used as a verification technique, then there may be requirements of using the same signature that was taken first up, to be used as a reference signature [13-16]. If an automated verification technique is to be implemented for signature verification than the time factor must be given a superior importance. Although many researchers are working on signature verification, but none of them has considered the time factor as yet, it is evident from the literature review. Most of the researchers are using the database that contains a large number of signatures, but they are not taken in a wide span of time. In this paper a lot of time is devoted to the data collection itself [17]. In this piece of research the data is collected over a time duration of up to 180 days. During the data collection special measures were taken so that the person who has contributed to this work must we unaware of these circumstances.

\section{FEATURE EXTRACTION}

The initial values of signature parameters are shown in Table 1. Table 2 indicates that how these parameters can be updated by the means of weighted coefficients.

Table 1. Initial Values of Variables for some Random Signatures

\begin{tabular}{|c|c|c|c|c|c|c|}
\hline Name & Reference Signature & Skewness & Kurtosis & $\begin{array}{l}\text { Ordinary } \\
\text { Moment }\end{array}$ & Entropy & Mean \\
\hline User 1 & & 2.4658 & 7.0801 & 34768743 & 0.5049 & 0.1117 \\
\hline User 2 & & 3.7947 & 15.3994 & 18672118 & 0.3181 & 0.0577 \\
\hline User 3 & & 3.5282 & 13.4479 & 22375958 & 0.3471 & 0.065 \\
\hline User 4 & & 4.2225 & 18.8293 & 14082420 & 0.2784 & 0.0481 \\
\hline User 5 & & 3.9915 & 16.9323 & 20621771 & 0.2989 & 0.053 \\
\hline User 6 & & 3.4838 & 13.1367 & 25565271 & 0.3522 & 0.0664 \\
\hline User 7 & & 3.7026 & 14.7094 & 13354156 & 0.3277 & 0.0601 \\
\hline User 8 & & 3.9971 & 16.9769 & 10993271 & 0.2984 & 0.0529 \\
\hline User 9 & & 4.0666 & 17.5373 & 14644231 & 0.292 & 0.0513 \\
\hline User 10 & & 3.4002 & 12.5613 & 28515080 & 0.3623 & 0.069 \\
\hline
\end{tabular}


Table 2. Coefficients Value After Every Sample Coefficients Values After Every Sample

\begin{tabular}{|c|c|c|c|c|c|c|c|c|c|}
\hline & \multicolumn{9}{|c|}{ Coefficients Values After Every Sample } \\
\hline \multirow{9}{*}{ 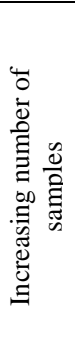 } & 1 & & & & & & & & \\
\hline & $1 / 2$ & $1 / 2$ & & & & & & & \\
\hline & $1 / 4$ & $1 / 4$ & $1 / 2$ & & & & & & \\
\hline & $1 / 8$ & $1 / 8$ & $1 / 4$ & $1 / 2$ & & & & & \\
\hline & $1 / 16$ & $1 / 16$ & $1 / 8$ & $1 / 4$ & $1 / 2$ & & & & \\
\hline & $1 / 32$ & $1 / 32$ & $1 / 16$ & $1 / 8$ & $1 / 4$ & $1 / 2$ & & & \\
\hline & $1 / 64$ & $1 / 64$ & $1 / 32$ & $1 / 16$ & $1 / 8$ & $1 / 4$ & $1 / 2$ & & \\
\hline & $1 / 128$ & $1 / 128$ & $1 / 64$ & $1 / 32$ & $1 / 16$ & $1 / 8$ & $1 / 4$ & $1 / 2$ & \\
\hline & $1 / 256$ & $1 / 256$ & $1 / 128$ & $1 / 64$ & $1 / 32$ & $1 / 16$ & $1 / 8$ & $1 / 4$ & $1 / 2$ \\
\hline
\end{tabular}

Figure 2 to Figure 6 depicts the variation of parameters as the samples are collected after a certain period of time. Table 3 indicates the values of signature parameters when these are updated in accordance with the weighted coefficients.

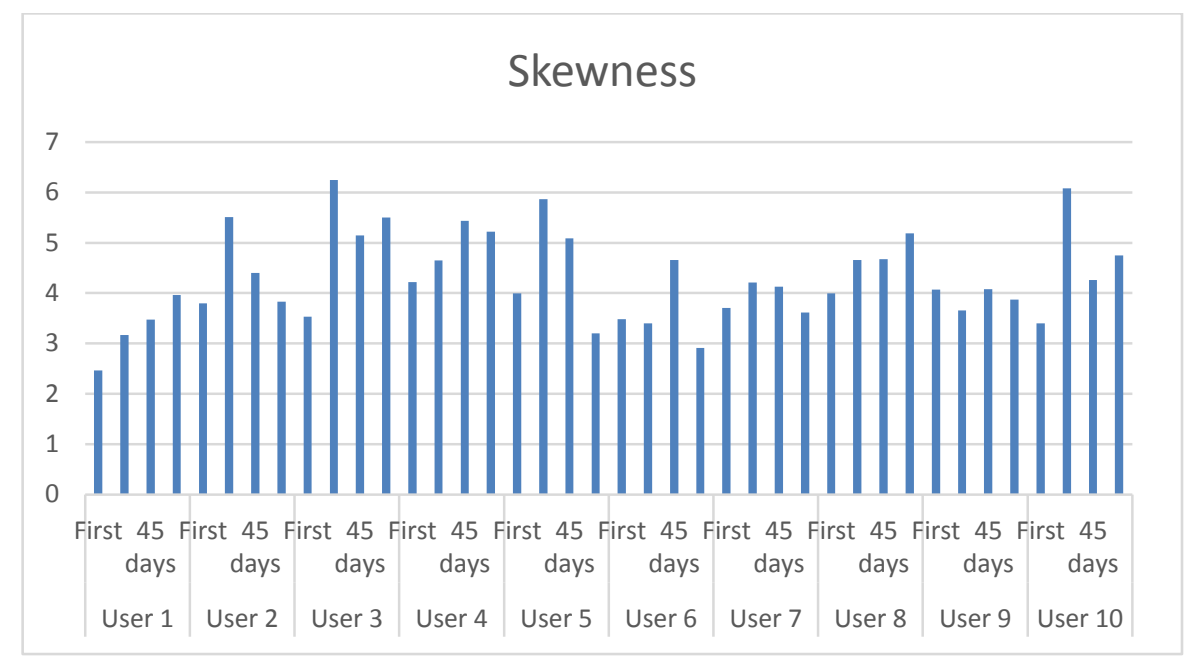

Figure 2. Variation of Skewness with Increasing Time for every User

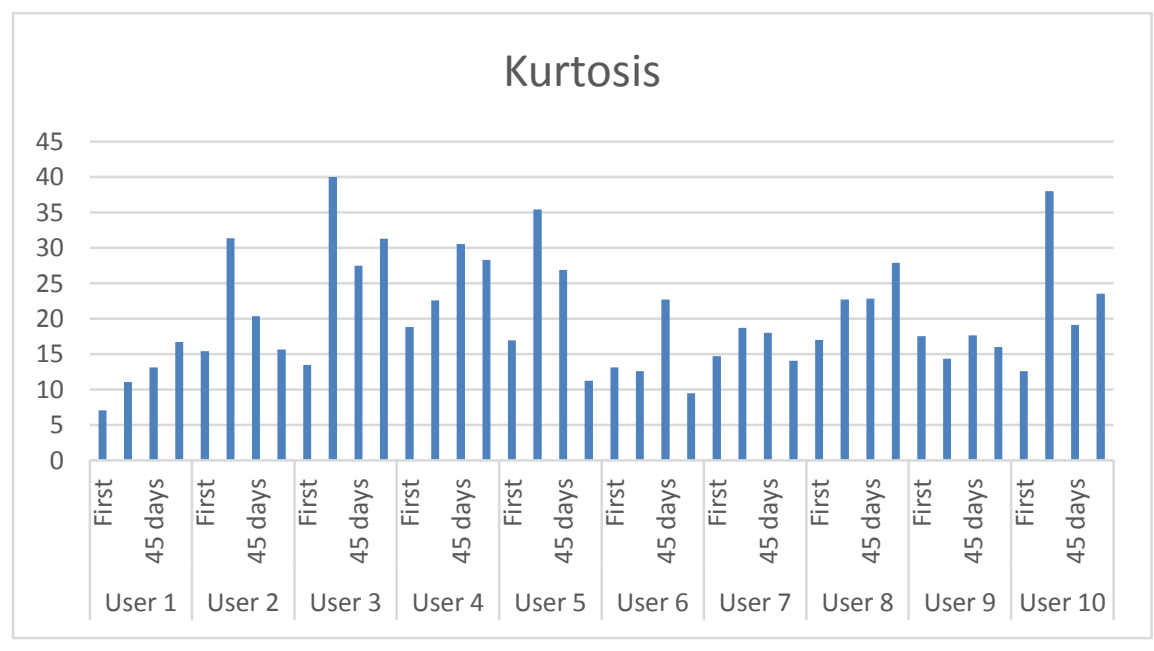

Figure 3. Variation of Kurtosis with Increasing Time for every User 


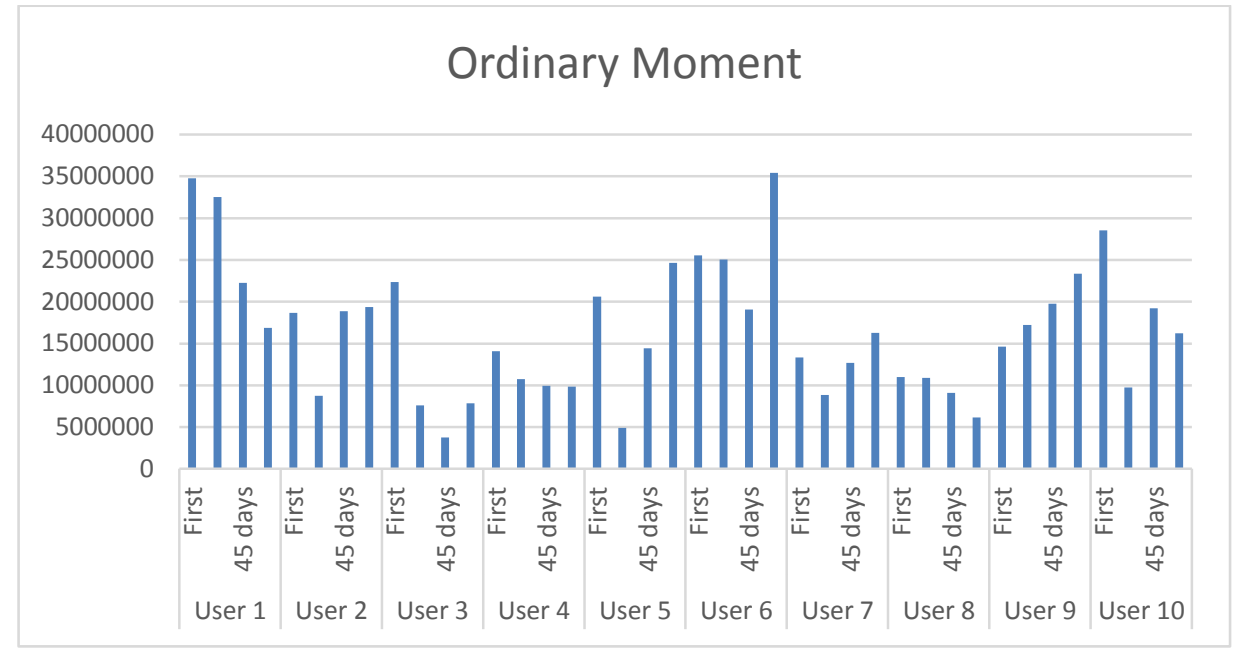

Figure 4. Variation of Ordinary Moment with Increasing Time for every User

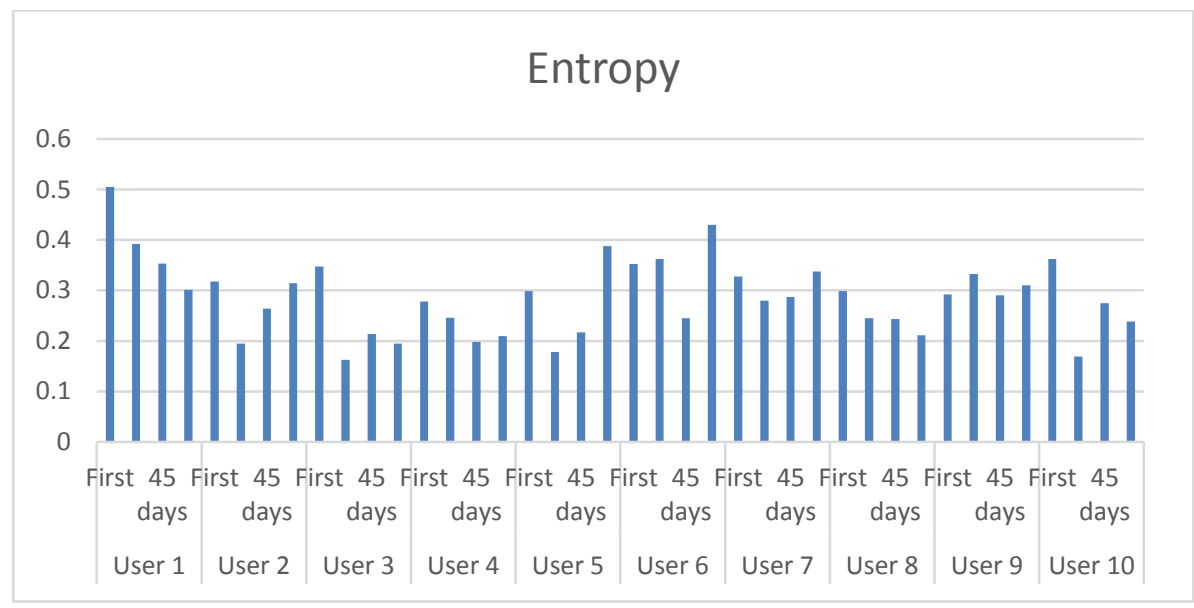

Figure 5. Variation of Entropy with Increasing Time for every User

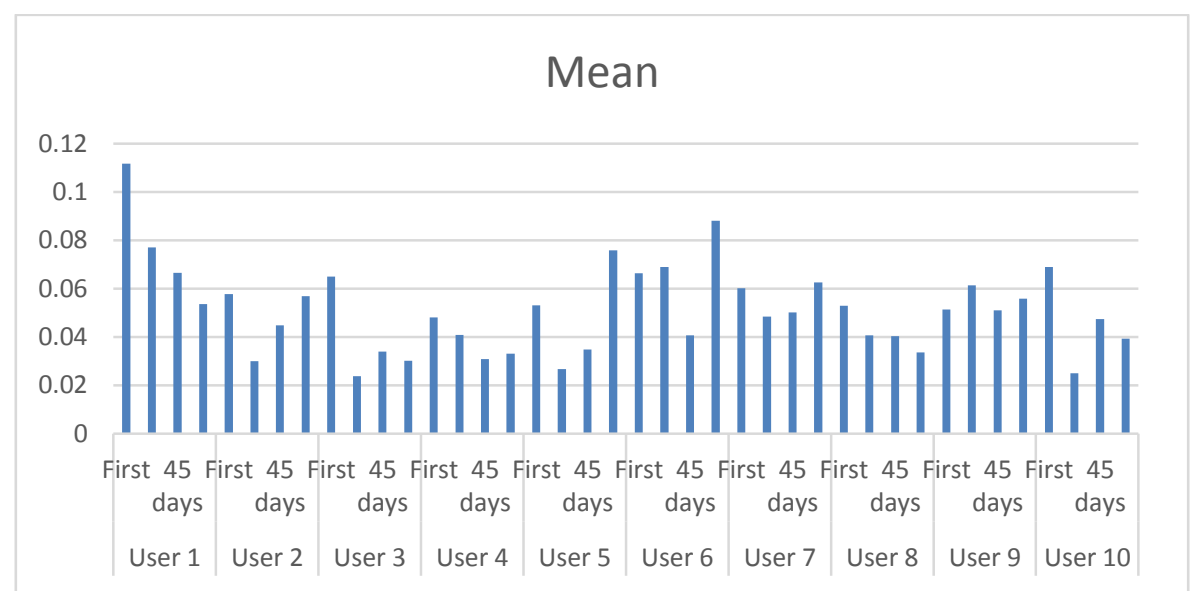

Figure 6. Variation of Mean with Increasing Time for every User 
Table 3. Weighted Average Values of Variables for some Random Signatures

\begin{tabular}{cccccc}
\hline Name & Skewness & Kurtosis & Ordinary Moment & Entropy & Mean \\
\hline User 1 & 3.555888 & 13.89604 & 22412972 & 0.3511 & 0.06705 \\
User 2 & 4.177988 & 18.76734 & 17840036 & 0.287325 & 0.050563 \\
User 3 & 5.259713 & 29.19308 & 8617448 & 0.214538 & 0.03465 \\
User 4 & 5.078488 & 26.94811 & 10503782 & 0.219838 & 0.035363 \\
User 5 & 4.105513 & 18.89209 & 19120116 & 0.307663 & 0.056588 \\
User 6 & 3.4786 & 13.61151 & 28801658 & 0.365475 & 0.071125 \\
User 7 & 3.827675 & 15.71574 & 14081362 & 0.316225 & 0.057338 \\
User 8 & 4.843888 & 24.62344 & 8095554 & 0.2346 & 0.038513 \\
User 9 & 3.921813 & 16.39945 & 20611242 & 0.305913 & 0.054725 \\
User 10 & 4.624538 & 22.88004 & 17689368 & 0.254488 & 0.0432 \\
\hline
\end{tabular}

\section{RESULTS AND DISCUSSION}

As shown in Table 4 the FAR and FRR parameters reduces significantly as more number of reference signatures are taken gradually. The parameters are averaged according to the weights shown in Table 3. Figure 2 shows the variations of skewness with increased number of reference signatures.

Table 4. FAR and FRR of Variables for some Random Signatures

\begin{tabular}{cccc}
\hline Time of Test & Number of tested samples & FAR $(\%)$ & FRR $(\%)$ \\
\hline Start & 150 & 7.2 & 6.9 \\
15 days & 150 & 6.7 & 6.8 \\
45 days & 150 & 5.9 & 6.2 \\
75 days & 150 & 4.9 & 5.2 \\
\hline
\end{tabular}

Table 5 compares the results of proposed scheme with some of the existing ones. It is evident that the continuous updation of signature parameters may provide the significant improvements in the system performance.

Table 5. Comparison with Existing Techniques

\begin{tabular}{ccc}
\hline Paper & FAR (\%) & FRR (\%) \\
\hline V Iranmanesh et al. [9] & 7.4 & 6.4 \\
A. Kholmatov et al. [10] & 7.84 & 10.54 \\
K. S. Radhika et al. [12] & 11.54 & 34.62 \\
Proposed Scheme & 4.9 & 5.2 \\
\hline
\end{tabular}

\section{CONCLUSION}

The time factor plays an important role in the framing of signature of an individual person. The signatures of a particular person is affected by the emotions and the physical condition at that very instant. Moreover due to ageing the signature of a person keeps on changing. If a rigid signature verification is used then the FAR and FRR will increase as the time passes by. In this paper the stored signatures are updated after a certain period of time and the weighted average of static parameters are used for verification. The results demonstrate a significant improvement in FAR and FRR.

\section{ACKNOWLEDGEMENT}

The authors would like to thank Director, National Institute of Technical Teachers' Training \& Research, Chandigarh, India for their constant inspirations and support throughout this research work.

\section{REFERENCES}

[1] D. Huang and G. Jian, "On-line Signature Verification Based on GA-SVM", International Journal of Online Engineering, Vol. 11, No. 6, pp. 49-53, 2015.

[2] J. Shin, T. Takanashi, "Online Signature Verification based on Pen Inclination and Pressure Information", International Journal of Electrical and Computer Engineering, Vol. 2, No. 4, pp. 441-446, 2012.

[3] Z. Honarpishesh, K. Faez, "Biometric Identification by Clustering the Dorsal Hand Vein Patterns using the Firefly Algorithm", International Journal of Electrical and Computer Engineering, Vol. 3, No. 1, pp. 30-41, 2013.

[4] A. Karouni, B. Daya, and S. Bahlak, "Offline signature recognition using neural networks approach", Procedia Comput. Sci., vol. 3, pp. 155-161, 2011. 
[5] A. Pansare, "Handwritten Signature Verification using Neural Network", International Journal of Applied Information Systems, Vol. 1, No. 2, pp. 44-49, 2012.

[6] I. Bhattacharya, P. Ghosh, and S. Biswas, "Offline Signature Verification Using Pixel Matching Technique", Procedia Technology 10: International Conference on Computational Intelligence Modeling Techniques and Applications (ICCIMTA), pp. 970-977, 2013.

[7] Y. Qiao and J. Liu, "Offline Signature Verification Using Online Handwriting Registration”, in Proc. IEEE Conf. CVPR, Jun. 2007, pp. 1-8.

[8] M. Yadav, A. Kumar, T. Patnaik, and B. Kumar, "A Survey on Offline Signature Verification”, vol. 2, no. 7, pp. 337-340, 2013.

[9] V. Iranmanesh, S. Mumtazah, S. Ahmad, W. Azizun, W. Adnan, S. Yussof, O. A. Arigbabu, and F. L. Malallah, "Online Handwritten Signature Verification using Neural Network Classifier Based on Principal Component Analysis", The Scientific World Journal, Vol. 2014, pp. 1-8, 2014.

[10] A. Kholmatov and B. Yanikoglu, "Identity Authentication using Improved Online Signature Verification Method", Pattern Recognition Letter, Vol. 26, No. 15, pp. 2400-2408, 2005.

[11] A.K. Jain, F.D. Griess, and S.D. Connell, "On-line Signature Verification", The Journal of the Pattern Recognition Society, Vol. 35, pp. 2963-2972, 2002.

[12] K.S. Radhika and S. Gopika, "Online and Offline Signature Verification: A Combined Approach", Procedia Procedia Computer Science 46- International Conference on Information and Communication Technologies (ICICT-2014), pp. 1593-1600, 2015.

[13] M. Vatsa, R. Singh, P. Mitra, and A. Noore, "Signature Verification using Static and Dynamic Features", International Conference on NEURAL Information Processing (ICONIP), pp. 350-355, 2004.

[14] S.D. Pawar, "A Survey on Signature Verification Approaches", International Journal of Computer Science and Information Technologies, Vol. 6, No. 2, pp. 1068-1072, 2015.

[15] N. Forhad, B. Poon, M.A. Amin, and H. Yan, "Online Signature Verification for Multi-modal Authentication using Smart Phone", Proceedings of International Multi-Conference of Engineering and Computer Scientists, pp. 18-21, 2015.

[16] S. Rashidi, A. Fallah, and F. Towhidkhah, "Feature Extraction Based DCT on Dynamic Signature Verification", Scientia Iranica, Transactions D: Computer Science and Engineering and Electrical Engineering, Vol. 19, No. 6, pp. 1810-1819, 2012.

[17] A. Pansare, "Handwritten Signature Verification using Neural Network", International Journal of Applied Information Systems, Vol. 1, No. 2, pp. 44-49, 2012.

\section{BIOGRAPHIES OF AUTHORS}

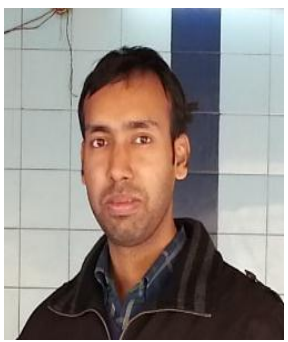

Manas Singhal received the B.Tech. degree in E\&C Engineering from GNIT, UPTU, Greater Noida, India in 2008. He is currently pursuing ME in E\&C Engineering from NITTTR, Panjab University, and Chandigarh, India.

$\mathrm{He}$ is currently working as an Assistant Professor in the Department of E\&C Engineering, MIT, and Moradabad, India. His current research and teaching interests are in Biometric Authentication, Digital Signal Processing, Digital Communication, and Digital Image Processing. He has authored till date 15 research publications out of which 11 are in Journals.

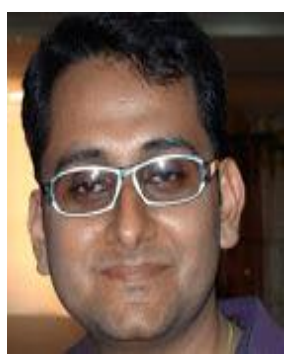

Manish Trikha received the B.Tech. degree in E\&C Engineering from MIT, Moradabad, India in 2007.He is currently pursuing ME in E\&C Engineering from NITTTR, Panjab University, Chandigarh, India.

He is currently working as an Assistant Professor in the Department of E\&C Engineering, MIT, and Moradabad, India. His current research and teaching interests are in digital signal processing and Digital electronics. He has authored till date 13 research publications that include 9 in International Journal and 4 in International Conferences.

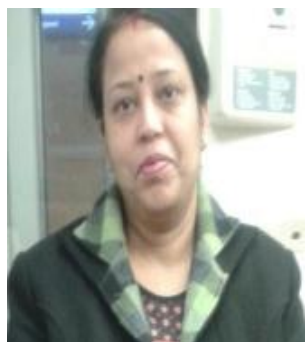

Dr. Maityree Dutta corrently working as a Professor and Head of the Department, Electronics and Communication Engineering, National Institute of Technical Teacher Training and Research (NITTTR), Chandigarh, India. Her area of interest includes Digital Image Processing, Neural Network. She has authored various papers in Journals and Conferences.

IJECE Vol. 6, No. 6, December $2016: 2658-2664$ 